\title{
FENÓIS DERIVADOS DA LIGNINA, CARBOIDRATOS E AMINOAÇÚCARES EM SERAPILHEIRA E SOLOS CULTIVADOS COM EUCALIPTO EM SISTEMAS CONVENCIONAL E FERTIRRIGADO ${ }^{1}$
}

\author{
Rodinei Facco Pegoraro ${ }^{2}$, Ivo Ribeiro Silva ${ }^{3}$, Roberto Ferreira Novais ${ }^{3}$, Nairan Felix Barros ${ }^{3}$ e Sebastião \\ Fonseca $^{4}$
}

\begin{abstract}
RESUMO - Este estudo teve por objetivo avaliar os teores de fenóis derivados de lignina, carboidratos e aminoaçúcares, bem como o estádio de decomposição e a contribuição de compostos de origens vegetal e microbiana para a matéria orgânica do solo (MOS) em sistemas de cultivo convencional e fertirrigado de eucalipto. Foram realizadas coletas de serapilheira e solo (Argissolo) em dois sistemas de cultivo de eucalipto (convencional e fertirrigado) em dois locais de coleta (linha e entrelinha), com três repetições. Foram avaliados a produção de serapilheira, os teores de C orgânico total (COT), $\mathrm{N}$ total (NT), lignina e fenóis derivados da lignina e suas relações entre grupamentos ácidos e aldeídos (Ac/Al), carboidratos e suas relações hexose/pentose, aminoaçúcares e a relação glucosamina/ácido murâmico no solo. O sistema de cultivo de eucalipto fertirrigado promoveu maior produção de serapilheira, diminuindo o teor de carboidratos, e não alterou o teor de lignina na serapilheira, em comparação com o convencional. No solo, o maior acúmulo de serapilheira (22\%) no sistema fertirrigado aumentou o teor de carboidratos totais, lignina e aminoaçúcares, principalmente nas entrelinhas de cultivo, em que foram amontoados e enterrados os resíduos da colheita anterior. Também houve aumento na relação hexoses/pentoses, indicando maior presença de compostos originários da comunidade microbiana na MOS. Entre os compostos de origem microbiana, observou-se maior presença de glucosamina, indicando maior contribuição fúngica para a formação da MOS do cultivo fertirrigado.
\end{abstract}

Palavras-chave: Matéria orgânica do solo; Relação hexoses/pentoses; Glucosamina.

\section{PHENOLS FROM LIGNIN, CARBOHYDRATES, AND AMINO SUGARS IN LITTER AND SOILS CULTIVATED WITH EUCALYPTUSIN CONVENTIONAL AND FERTIRRIGATED SYSTEM}

\begin{abstract}
The study aimed to evaluate the content of phenols derived from lignin, carbohydrates, amino sugars, the stage of decomposition of compounds and the relative contribution of plant-and microbialderived compounds to the soil organic matter (SOM) in the conventional and fertirrigated till age of eucalyptus. Samples of litter and soil (Ultisol) were taken from two tillage systems (conventional and fertirrigated) at two collection sites (line and between-line) with three replications. It was evaluated the litter production, content of total organic C (TOC), total $N(T N)$, lignin and phenols-derived lignin and its Ac/Alratio, carbohydrates and their hexose/pentose ratio, amino sugars and the glucosamine/muramic acid ratio in the soil. The cultivation of eucalyptus in fertirrigated system promoted higher litter fall, reduced the carbohydrate content and maintained the content of lignin in the litter in comparison to the conventional system. In soil, the greater accumulation of the litter (22\%) in fertirrigated system increased the contents of carbohydrates,
\end{abstract}

\footnotetext{
${ }^{1}$ Recebido em 07.10.2011 aceito para publicação em 12.05.2013.

${ }^{2}$ Universidade Estadual de Montes Claros, Departamento de Ciências Agrárias. UNIMONTES, Brasil. E-mail: $<$ rodinei_pegoraro@yahoo.com.br>.

${ }^{3}$ Departamento de Solos da Universidade Federal de Viçosa, UFV, Brasil. E-mail: <ivosilva@ufv.br>, <rfnovais@ufv.br>e <nfbarros@ufv.br>.

${ }^{4}$ Pesquisador na Fibria, Aracruz - Espírito Santo, ES. E-mail: <sf@ fibria.com.br>.
} 
lignin and amino sugars, mainly in the between-lines position. The hexoses/pentoses ratio also increased, indicating a greater presence of compounds of microbial origin. Among the compounds of microbial origin, a larger abundance of glucosamine was observed, indicating a greater contribution of fungal to the SOM formation under fertirrigated cultivation.

Keywords: Soil organic matter; Hexoses/pentoses ratio; Glucosamine.

\section{INTRODUÇÃO}

Cultivos intensivos de espécies florestais utilizando fertilizantes e irrigação podem levar ao aumento da produtividade (STAPE et al., 2004) e aporte de resíduos ao solo (LEGGETT; KELTING, 2006), fato que altera a estrutura da serapilheira e a atividade microbiana do solo (SJÖBERG et al., 2004; BAUMANN et al., 2009). Essa técnica de cultivo tem demonstrado maior eficácia em aumentar C e N no solo (MADEIRA et al., 2002; LI et al., 2006), possivelmente por estreitar a relação $\mathrm{C} / \mathrm{N}$ e lignina/ $\mathrm{N}$, aumentar a labilidade da serapilheira e favorecer a estabilização da matéria orgânica do solo (MOS) nativa (FORRESTER et al., 2006).

O incremento do teor de carboidratos provenientes da celulose e da hemicelulose, nos resíduos vegetais de eucalipto irrigado e fertilizado, tem aumentado a contribuição de compostos orgânicos derivados da atividade microbiana do solo na formação da MOS (MADEIRA et al., 2002). Essa contribuição pode ser mensurada pela relação entre açúcares derivados da atividade microbiana (hexoses) e açúcares derivados de plantas (pentoses) (MÖLLER et al., 2002; PEGORARO et al., 2011a).

Além dos carboidratos, os resíduos de eucalipto apresentam teores consideráveis de lignina, biopolímero considerado de limitada decomposição pelos microrganismos devido à sua maior complexidade estrutural (HEIM; SCHMIDT, 2007). No entanto, pode-se hipotetizar que resíduos vegetais produzidos em cultivos fertirrigados são mais abundantes e decomponíveis aos microrganismos. Com isso, ter-se-ia um processo mais acelerado de decomposição de restos culturais no solo (LEITE et al., 2003), aumentando o estado de oxidação de compostos fenólicos (lignina) (SJÖBERG et al., 2004), o que interfere na estabilização do C na MOS. Os diferentes estádios de decomposição ou humificação desses compostos podem ser identificados pelo teor de grupamentos ácidos e aldeídos da lignina no solo (relação Ac/Al), sendo o grau de humificação proporcional ao valor obtido para a relação Ac/Al (OTTO; SIMPSON, 2006).

Revista Árvore, Viçosa-MG, v.37, n.3, p.519-529, 2013
Indicadores da contribuição da comunidade microbiana para a formação e estabilização da MOS podem ser obtidos indiretamente pela quantificação de aminoaçúcares, como glucosamina e galactosamina, e ácido murâmico, remanescentes da atividade microbiana no solo. Comunidades fúngicas originam predominantemente a glucosamina e as bactérias, o ácido murâmico e a galactosamina (GLASER et al., 2004). Já os actinomicetos são menos específicos e podem produzir a glucosamina e menores quantidades de ácido murâmico (GLASER et al., 2004). Com isso, as relações entre os aminoaçúcares (glucosamina/ácido murâmico) podem servir como indicadores da contribuição fúngica e bacteriana para a MOS (GLASER et al., 2004; LIANG et al., 2007). Em solos de eucalipto, no entanto, há poucos estudos que relatem as alterações provocadas pela intensificação do uso da água e de nutrientes na qualidade dos resíduos vegetais produzidos e na contribuição da comunidade microbiana para a MOS.

Alterações no manejo cultural, com a utilização de cultivo de acácia (Acacia mangium Willd.) após o monocultivo de eucalipto, implicaram maior disponibilidade de $\mathrm{N}$ e relação glucosamina/ácido murâmico no solo, em comparação com o monocultivo de eucalipto de ciclo curto (sete anos), indicando maior participação de fungos na comunidade microbiana e recuperação na qualidade do solo com acácia, também pelo aumento do teor de COT (PEGORARO et al., 2012).

Este estudo teve por objetivo avaliar os teores de fenóis (derivados de lignina), carboidratos e aminoaçúcares, o estádio de decomposição e a contribuição de compostos de origem vegetal e microbiana para a MOS, em sistemas de cultivo convencional e fertirrigado de eucalipto.

\section{MATERIAL E MÉTODOS}

O estudo foi realizado no Município de Aracruz, ES, localizado a $19^{\circ} 48^{\prime} \mathrm{S}$ e $40^{\circ} 17^{\prime} \mathrm{W}$, onde foram selecionadas áreas cultivadas com eucalipto em sistemas convencional e fertirrigado. O clima da região é do

Revista Árvore, Viçosa-MG, v.37, n.3, p.519-529, 2013 
tipo Aw, segundo a classificação de Köppen (OMETTO, 1981), com temperatura e precipitação pluvial média anual de $23{ }^{\circ} \mathrm{Ce} 1.400 \mathrm{~mm}^{\circ} \mathrm{ano}^{-1}$, respectivamente. $\mathrm{O}$ local representa microbacia típica da região dos Tabuleiros Costeiros, cujo solo foi caracterizado como Argissolo Amarelo fase floresta tropical subperenifólia, derivado do grupo Barreiras.

Os tratamentos foram distribuídos em esquema fatorial $2 \times 2$ e consistiram de dois sistemas de cultivo (convencional-EC e fertirrigado-EF) e dois locais de coleta de solo (linha-L e entre linha-EL do plantio atual, em que foram localizados os restos vegetais do cultivo anterior de eucalipto).O delineamento adotado foi o de blocos casualizados com três repetições. Até a época da coleta das amostras de solo, as áreas (talhões) selecionadas de eucalipto já tinham sido cultivadas por 28 anos (quatro ciclos) com essa cultura.

O último plantio de eucalipto foi realizado em 1998, com plantas provenientes de híbridos clonais de Eucalyptus grandis $\mathrm{x}$ E. urophyla, cultivados em sistema de reforma e espaçamento entre plantas de $3 \times 3 \mathrm{~m}$. Após 90 dias do plantio, as plantas do tratamento convencional receberam $350 \mathrm{~kg} \mathrm{ha}^{-1}$ de fosfato natural e, no final do primeiro ano, mais $160 \mathrm{~kg} \mathrm{ha}^{-1}$ de NPK 6-30-6. As plantas cultivadas no sistema fertirrigado, que visou ao suprimento maximizado de água e nutrientes, foram adubadas com $600 \mathrm{~kg} \mathrm{ha}^{-1} \mathrm{de} \mathrm{Ca} \mathrm{e}$ $300 \mathrm{~kg} \mathrm{ha}^{-1}$ de $\mathrm{Mg}$ (como calcário dolomítico), $4 \mathrm{~kg} \mathrm{ha}^{-1}$ de B, $2 \mathrm{~kg}$ de $\mathrm{Cu}$ e $2 \mathrm{~kg}$ de $\mathrm{Zn}$, seguido por fertilizações trimestrais com $126 \mathrm{~kg} \mathrm{ha}^{-1}$ de $\mathrm{N}$ (como sulfato de amônio), $21 \mathrm{~kg} \mathrm{ha}^{-1} \mathrm{de} \mathrm{P}$ (como superfosfato simples) e $79 \mathrm{~kg} \mathrm{ha}^{-1}$ de $\mathrm{K}$ (como cloreto de potássio). A adição de água via irrigação foi por gotejamento (35 mm por semana), baseada no balanço hídrico da região que mostrou potencial médio de evapotranspiração de $28 \pm$ $2 \mathrm{~mm}$ por semana (STAPE et al., 1997). Um pluviômetro foi instalado na área, sendo o volume de água para aplicação durante uma semana baseado na precipitação pluvial das semanas anteriores (se a precipitação fosse maior que $35 \mathrm{~mm}$ na semana anterior, não era realizada irrigação na semana seguinte). A taxa de irrigação do sistema foi checada mensalmente (STAPE et al., 2004).

Nas áreas de cultivos convencional e fertirrigado foram selecionados talhões e coletadas três amostras compostas de solo, nas linhas e entrelinhas do eucalipto (profundidade de 0-10 cm). Em cada talhão foram coletadas amostras indeformadas com anéis volumétricos nessa camada, para se estimar a densidade aparente do solo.
As amostras de solo foram coletadas na época chuvosa (janeiro/fevereiro), e os povoamentos de eucalipto estavam no final da rotação (seis anos). Depois de coletadas, as amostras de solo foram imediatamente secas ao ar, destorroadas, passadas em peneira com malha de $2 \mathrm{~mm}$ e homogeneizadas, retirando-se subamostras para caracterizações química e da densidade do solo. Foram obtidos os seguintes resultados, no cultivo de eucalipto em sistemas convencional e fertirrigado, respectivamente: $\mathrm{pH}\left(\mathrm{H}_{2} \mathrm{O}\right)=5,1 \mathrm{e} 5,1 ; \mathrm{Ca}^{2+}=0,9$ e $1,9 \mathrm{cmol}_{\mathrm{c}}$ $\mathrm{dm}^{-3} \mathrm{e} \mathrm{Mg}^{2+}=0,3$ e $0,4 \mathrm{cmol}_{\mathrm{c}} \mathrm{dm}^{-3}\left(\mathrm{KCl}-1 \mathrm{~mol} \mathrm{~L}^{-1}\right) ; \mathrm{H}+\mathrm{Al}$ $=1,5$ e $3,6 \mathrm{cmol}_{\mathrm{c}} \mathrm{dm}^{-3}$ (acetato de cálcio $0,5 \mathrm{~mol} \mathrm{~L}^{-1}$ pH 7,0); P = 5,1 e 23,4 $\mathrm{mg} \mathrm{dm}^{-3} ; \mathrm{K}=13,0$ e $38,5 \mathrm{mg} \mathrm{dm}^{-3}$ (Mehlich 1); e densidade $=1,5$ e $1,4 \mathrm{~kg} \mathrm{dm}^{-3}$.

A serapilheira na superfície do solo foi amostrada por ocasião da coleta das amostras de solo. Dentro de cada área dos tratamentos selecionados foram identificados três pontos (repetições), alocados aleatoriamente, em que se lançou um gabarito com $0,25 \mathrm{~m}^{2}$ de área $(0,5 \mathrm{x}$ $0,5 \mathrm{~m}$ ). Após a coleta, as amostras de serapilheira foram secas em estufa $\left(65^{\circ} \mathrm{C}\right.$ por $\left.72 \mathrm{~h}\right)$ até massa constante, para determinação da matéria seca total e teores de lignina e carboidratos nos resíduos grossos (galhos grossos, com diâmetro maior que $5 \mathrm{~mm}$ ) e resíduos finos (composto por galhos finos, cascas e folhas). Para fins de análise estatística da serapilheira, adotou-se o delineamento em blocos ao acaso com três repetições, em esquema fatorial 2 x 2 , que consistiu de dois sistemas de cultivo (convencional-EC e fertirrigado-EF) e dois tipos de resíduos vegetais (resíduos grossos e resíduos finos).

Nas amostras de serapilheira, efetuaram-se análises de C orgânico total (COT) e $\mathrm{N}$ total, por meio da combustão via seca em analisador elementar CHNS (Perkin Elmer CHNS/ O 2400) e, no solo, análises de COT e N total, segundo Yeomans e Bremner (1988) e Bataglia et al. (1983), respectivamente. Também foram quantificados os teores de fenóis derivados de lignina (VSC), carboidratos, aminoaçúcares derivados da atividade microbiana no solo e suas relações, conforme descrito nos tópicos subsequentes.

\subsection{Oxidação da lignina (VSC) com CuO e análise dos derivados por cromatografia líquida}

A degradação termoquímica da lignina contida nas frações da MOS foi realizada pelo método de oxidação com CuOem micro-ondas (GOÑI; MONTGOMERY, 2000). Amostras de solo e resíduos vegetais (passados na peneira de $60 \mathrm{mesh}$ ) foram acondicionadas em tubos

Revista Árvore, Viçosa-MG, v.37, n.3, p.519-529, 2013 
de teflon contendo de 2 a 5 mg de C orgânico, juntamente com $500 \mathrm{mg}$ de $\mathrm{CuO}, 50 \mathrm{mg}$ de sulfato ferroso amoniacal e $15 \mathrm{~mL}$ de $\mathrm{NaOH} 2 \mathrm{~mol} \mathrm{~L}^{-1}$. A mistura foi aquecida em micro-ondas, em ambiente de $\mathrm{N}_{2}$, com pressão de trabalho entre 60 e 70 psi, durante 90 min. A essa pressão, atingiu-se temperatura de $150{ }^{\circ} \mathrm{C}$. Após a mistura ter esfriado, ela foi transferida para tubos de centrífuga de $50 \mathrm{~mL}$ e centrifugada a $1.844 \mathrm{xg}$, por $10 \mathrm{~min}$. Essa etapa foi repetida por mais duas vezes, adicionando-se $5 \mathrm{~mL}$ de $\mathrm{NaOH}$ $1 \mathrm{~mol} \mathrm{~L}^{-1}$ por repetição. O sobrenadante alcalino foi acidificado para $\mathrm{pH} 1 \mathrm{com}$ adição de aproximadamente $4 \mathrm{~mL}$ de $\mathrm{HCl}$ concentrado. Para capturar os monômeros de lignina, misturaram-se $6 \mathrm{~mL}$ de acetado de etila com o sobrenadante em erlenmeyer de vidro. A fase orgânica foi transferida para tubos de vidro, repetindo-se a etapa por mais duas vezes. Possíveis resquícios de água foram removidos com a adição de $\mathrm{Na}_{2} \mathrm{SO}_{4}$. Então, solidificou-se a amostra em concentrador a vácuo $\left(45^{\circ} \mathrm{C}\right)$. As amostras foram readissolvidas em $5 \mathrm{~mL}$ de água ultrapura com o auxílio de sonda de ultrassom, para facilitar a solubilização dos compostos em água. Depois de ser passada em filtro de náilon de $0,45 \mu \mathrm{m}$, pipetou-se $0,5 \mathrm{~mL}$ dessa solução aquosa para frascos do amostrador automático e, então, fizeram-se a identificação e quantificação dos derivados de lignina por cromatografia iônica (DX 600 Dionex, Sunnyvale, CA, EUA).

Os fenóis quantificados dessa oxidação foram os monômeros do grupo vanilil (V), siringil (S) e cinamil (C). Os monômeros dos grupos $\mathrm{V}$ e $\mathrm{S}$ foram calculados de correspondentes aldeídos, cetonas e ácidos carboxílicos: $\mathrm{V}$ = vanilin + acetovanilona + ácido vanílico; $\mathrm{S}=$ siringaldeído + acetossiringona + ácido siríngico. Os monômeros do grupo $\mathrm{C}$ foram derivados do somatório de ácido p-cumárico e ácido ferúlico. Considerou-se o VSC ( $\mathrm{g} \mathrm{kg}^{-1}$ de serapilheira e $\mathrm{mg} \mathrm{kg}^{-1}$ de solo) como o somatório desses três grupos, os quais corresponderam ao teor de lignina oxidada com $\mathrm{CuO}$ em micro-ondas. Usando as relações de massa entre ácidos carboxílicos (Ac) e aldeídos (Al) nos grupos vanilil (V) e siringil (S), expressos, respectivamente, como $(\mathrm{Ac} / \mathrm{Al})_{\mathrm{V}}$ e $(\mathrm{Ac} /$ $\mathrm{Al})_{\mathrm{S}}$, estimou-se o grau de decomposição (oxidação) da lignina (OTTO; SIMPSON, 2006).

\subsection{Separação e quantificação de carboidratos}

Subamostras de solo (100 mg) e resíduos vegetais (20 mg) foram moídas em moinho de bola, peneiradas (60 mesh), pesadas e acondicionadas em tubos de ensaio; adicionaram-se $800 \mu \mathrm{L}$ de $\mathrm{H}_{2} \mathrm{SO}_{4} 6 \mathrm{~mol} \mathrm{~L}^{-1}$ e, então, as

Revista Árvore, Viçosa-MG, v.37, n.3, p.519-529, 2013 amostras foram homogeneizadas por meio de agitação manual. Esperaram-se $30 \mathrm{~min}$, e procedeu-se à diluição das amostras por meio de adição de 4,2 $\mathrm{mL}$ de água ultrapura, com o intuito de atingir uma concentração final de $1 \mathrm{~mol} \mathrm{~L}^{-1} \mathrm{de}_{2} \mathrm{SO}_{4}$. As amostras foram tampadas com papel laminado, vedadas com cordão de borracha e aquecidas em autoclave por $30 \mathrm{~min}$, na temperatura de $121^{\circ} \mathrm{C}(104 \mathrm{kPa})$. Esperou-se que as amostras esfriassem na temperatura ambiente para prosseguir com a centrifugação (1.844 xg) por $10 \mathrm{~min}$, separando o sobrenadante do resíduo. Esse procedimento foi repetido por mais duas vezes com a adição de $1 \mathrm{~mL}$ de água ultrapura, objetivando a máxima recuperação do conteúdo de compostos orgânicos solúveis do resíduo. Segundo Martens e Loeffelmann (2002), esse procedimento não consegue extrair totalmente os monômeros de celulose e hemicelulose dos resíduos vegetais. Portanto, conforme sugerido por esses autores, para melhorar essa taxa de recuperação levaram-se os resíduos da primeira extração à estufa $\left(60^{\circ} \mathrm{C}\right)$ até a secagem da amostra. Após, adicionaram-se $300 \mu \mathrm{L}$ de $\mathrm{H}_{2} \mathrm{SO}_{4}, 18 \mathrm{~mol} \mathrm{~L}^{-1}$ e esperaram-se 30 min para, novamente, realizar a diluição da solução com $3,6 \mathrm{~mL}$ de água ultrapura, atingindo a concentração final de $1 \mathrm{~mol} \mathrm{~L}^{-1} \mathrm{de}_{2} \mathrm{SO}_{4}$. $\mathrm{O}$ frasco foi vedado e autoclavado por $30 \mathrm{~min} \mathrm{na}$ temperatura de $121^{\circ} \mathrm{C}(104 \mathrm{kPa})$. Quando a solução retornou à temperatura ambiente, ela foi centrifugada (1.844 xg) por 10 min e, então, retirou-se o sobrenadante. Esse passo foi repetido por mais duas vezes, adicionando-se $1 \mathrm{~mL}$ de água ultrapura antes de cada centrifugação. O sobrenadante da primeira fase foi misturado com o da segunda em tubos de 20 mL e diluído 100 vezes. As amostras foram passadas em filtro de náilon de $0,45 \mu \mathrm{m}$ e, então, pipetou-se $0,5 \mathrm{~mL}$ para identificação e quantificação dos monômeros de carboidratos por cromatografia iônica.

\subsection{Separação e quantificação de aminoaçúcares}

Os aminoaçúcares glucosamina (Gluc) e galactosamina (Galac), e o ácido murâmico (Ác Mur) foram extraídos do solo conforme Zhang e Amelung (1996). Subamostras contendo, aproximadamente, $0,3 \mathrm{mg}$ de $\mathrm{N}$, juntamente com um padrão interno (myoinositol), foram acondicionadas em tubos de vidro com tampa de teflon e hidrolisadas com $\mathrm{HCl} 6 \mathrm{~mol} \mathrm{~L}^{-1}$ a $105^{\circ} \mathrm{C}$ por $8 \mathrm{~h}$, em ambiente de $\mathrm{N}_{2}$. O hidrolisado foi centrifugado $(1.844 \mathrm{xg})$ por $10 \mathrm{~min}\left(4^{\circ} \mathrm{C}\right)$. O sobrenadante foi transferido para tubos de vidro e concentrado sob vácuo a $40{ }^{\circ} \mathrm{C}$. A amostra foi redissolvida em $20 \mathrm{~mL}$ 
de água ultrapura, e ajustou-se o pH da solução para 6,6-6,8 com KOH 0,4 mol L-1. Após neutralizar a solução com $\mathrm{KOH}$ para precipitar o $\mathrm{Fe}$, a mistura foi centrifugada, novamente, durante $15 \mathrm{~min}$ a $1.884 \mathrm{xg}\left(4^{\circ} \mathrm{C}\right)$, em tubos de centrífuga de $50 \mathrm{~mL}$. O sobrenadante foi concentrado e rediluído em $1 \mathrm{~mL}$ de água. As frações de aminoaçúcares do sobrenadante foram rapidamente congeladas. Após a filtragem por membranas de náilon de $0,45 \mu \mathrm{m}$, utilizou-se $0,5 \mathrm{~mL}$ da solução para identificação e quantificação dos aminoaçúcares por cromatografia iônica. Todo o sistema cromatográfico era controlado por meio do software Chromeleon (Dionex).

\subsection{Análise estatística dos resultados}

Os resultados foram analisados no programa estatístico SAEG 5.0 e as médias dos tratamentos, comparadas por meio do teste de LSD de Fisher $(\mathrm{p}<5 \%)$ protegido (STEEL et al., 1997), ou seja, foram realizadas comparações múltiplas apenas quando o teste $\mathrm{F}$ da análise de variância foi significativo $(\mathrm{p}<5 \%)$.

\section{RESULTADOS}

\subsection{Teores totais de fenóis derivados de lignina (VSC) e carboidratos na serapilheira}

Por meio da análise de variância, observou-se interação entre sistemas de cultivo (convencional e fertirrigado) e tipos de resíduos vegetais (resíduos grossos e finos) para massa de matéria seca da serapilheira e teor de carboidratos e para as relações C/N e VSC/ Carb (Tabela 1). O teor de COT, NT e VSC e a relação
VSC/N diferiram apenas entre os tipos de resíduos estudados (Tabela 2). O cultivo do eucalipto no sistema fertirrigado propiciou incremento na produção de serapilheira, especialmente de resíduos finos, e não alterou os teores totais de lignina (VSC), COT e NT e a relação VSC/N, bem como reduziu o teor total de carboidratos na serapilheira, em comparação com o eucalipto cultivado no sistema convencional (Tabela 1).

Os resíduos menos lenhosos da serapilheira de eucalipto convencional (EC) apresentaram maior relação Ac/Al nos grupamentos vanilil e siringil (Figura 1), indicando estágio mais avançado de oxidação (decomposição) da lignina dos resíduos nesse sistema de manejo. Isso pode ser justificado pela menor deposição de resíduos vegetais novos decorrentes da menor produtividade no sistema convencional, contribuindo para a maior utilização da lignina de resíduos finos da serapilheira por fungos decompositores. Adicionalmente, a menor suscetibilidade de resíduos mais lenhosos à degradação enzimática pode justificar a menor relação Ac/Al nos resíduos grossos, em comparação com os resíduos finos.

\subsection{Teor de fenóis derivados de lignina (VSC), carboidratos e aminoaçúcares no solo}

Por meio da análise de variância, observou-se interação entre os sistemas de cultivo (EC e EF) e locais de coleta de solo (L e EL) para os teores de COT, NT, VSC, carboidratos e relações ácidos/aldeídos do grupamento siringil da lignina (Ac/Al), hexose/pentose (H/P) e glucosamina/ácido murâmico (Gluc/Ác mur)

Tabela 1 - Matéria seca total (MS), teores médios de carboidratos totais (carboidratos) e relação C/N e VSC/Carb nos resíduos grossos e finos da serapilheira de povoamentos de eucalipto nos sistemas convencional e fertirrigado, nos Tabuleiros Costeiros do Espírito Santo.

Table 1 - Total dry matter (DM), average content of total carbohydrates (carbs) and C/N and VSC/Carb ratio in the coarse and fine residue of litter of eucalypt plantation in conventional and fertirrigated systems in the Coastal Plains of Espírito Santo.

\begin{tabular}{|c|c|c|c|c|c|c|c|c|}
\hline \multirow[b]{2}{*}{ Cultivo } & \multicolumn{2}{|c|}{ Matéria seca } & \multicolumn{2}{|c|}{ Carboidratos } & \multicolumn{2}{|c|}{$\mathrm{C} / \mathrm{N}$} & \multicolumn{2}{|c|}{ VSC/Carb } \\
\hline & $\begin{array}{c}\text { Resíduo } \\
\text { grosso }\end{array}$ & $\begin{array}{l}\text { Resíduo } \\
\text { fino }\end{array}$ & $\begin{array}{c}\text { Resíduo } \\
\text { grosso }\end{array}$ & $\begin{array}{c}\text { Resíduo } \\
\text { fino }\end{array}$ & $\begin{array}{l}\text { Resíduo } \\
\text { grosso }\end{array}$ & $\begin{array}{l}\text { Resíduo } \\
\text { fino }\end{array}$ & $\begin{array}{c}\text { Resíduo } \\
\text { grosso }\end{array}$ & $\begin{array}{l}\text { Resíduo } \\
\text { fino }\end{array}$ \\
\hline & \multicolumn{2}{|c|}{$-\mathrm{t} \mathrm{ha}{ }^{-1}$} & \multicolumn{2}{|c|}{$-\mathrm{g} \mathrm{kg}^{-}$} & & & & \\
\hline Convencional & $8,2 \mathrm{aA}$ & $6,0 \mathrm{aB}$ & $702,6 \mathrm{aA}$ & $439,8 \mathrm{bA}$ & 293,0aA & $58,6 \mathrm{bA}$ & $0,12 \mathrm{aB}$ & $0,06 \mathrm{bB}$ \\
\hline Fertirrigado & $9,1 \mathrm{bA}$ & $14,0 \mathrm{aA}$ & $484,7 \mathrm{aB}$ & $358,0 \mathrm{bB}$ & $264,8 \mathrm{aB}$ & $69,2 \mathrm{bA}$ & $0,20 \mathrm{aA}$ & $0,09 \mathrm{bA}$ \\
\hline Média & \multicolumn{2}{|c|}{9,3} & \multicolumn{2}{|c|}{496,5} & \multicolumn{2}{|c|}{171,4} & \multicolumn{2}{|c|}{0,11} \\
\hline Sig. Int. (\%) & \multicolumn{2}{|c|}{3,0} & \multicolumn{2}{|c|}{1,7} & \multicolumn{2}{|c|}{0,0} & \multicolumn{2}{|c|}{0,00} \\
\hline C. V. $(\%)$ & \multicolumn{2}{|c|}{23,6} & \multicolumn{2}{|c|}{7,4} & \multicolumn{2}{|c|}{7,3} & \multicolumn{2}{|c|}{12,40} \\
\hline
\end{tabular}

Médias seguidas da mesma letra minúscula na linha e maiúscula na coluna não diferem entre si a 5\%, pelo teste LSD de Fisher protegido. Sig. Int. (\%): significância da interação entre sistemas de cultivo (convencional e fertirrigado) versus resíduos da serapilheira (resíduos grossos e finos) utilizados no estudo, em porcentagem. C. V. (\%): coeficiente de variação, em porcentagem. 


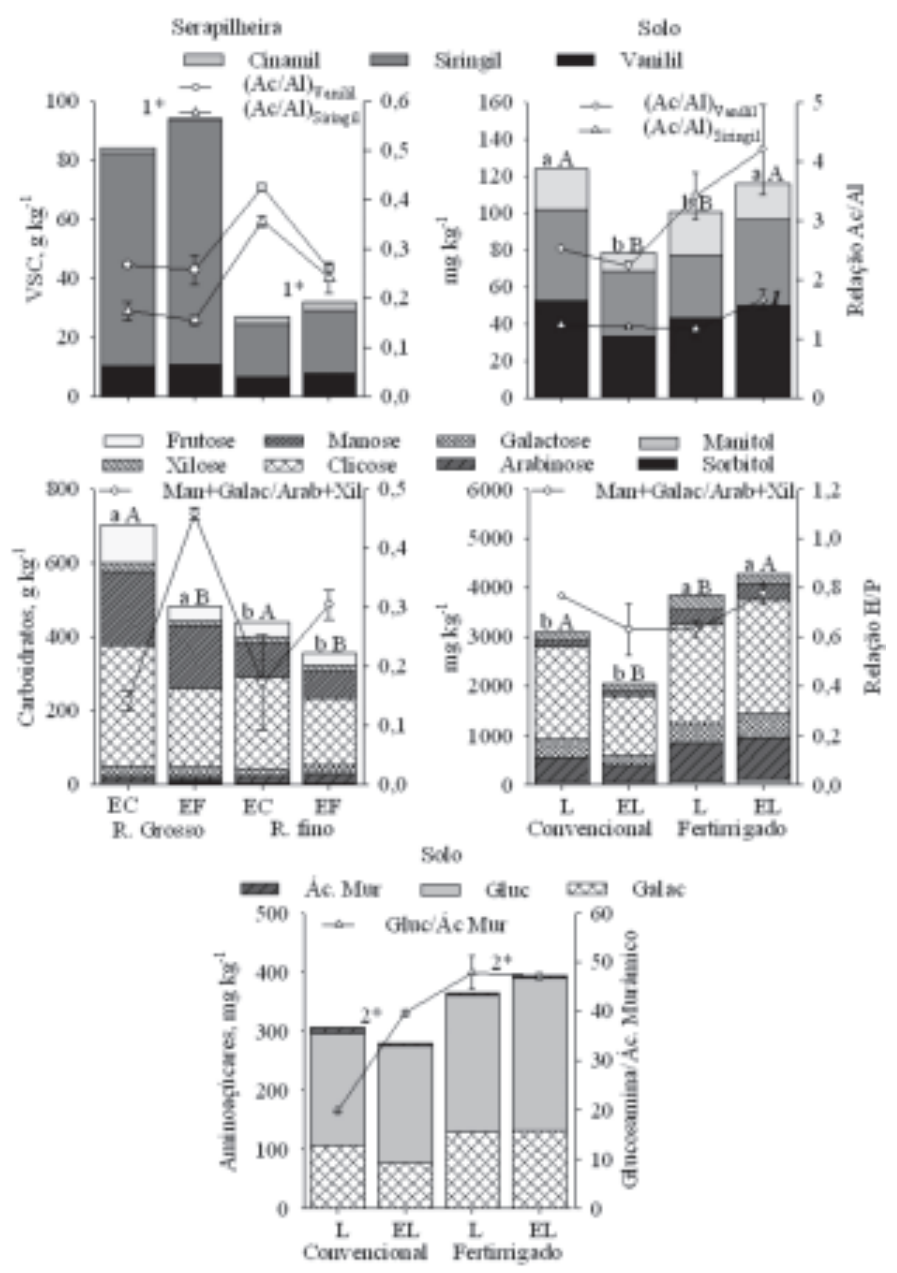

Figura 1 - Teores de fenóis derivados de lignina (VSC: Vanilil, Siringil e Cinamil) e carboidratos nos resíduos grossos (R. Grosso) e finos (R. Fino) da serapilheira de eucaliptos convencional (EC) e fertirrigado (EF) e teores de fenóis derivados de lignina (VSC), carboidratos e aminoaçúcares em amostras de solo coletadas na linha (L) e entrelinhas (EL) de cultivo de eucalipto convencional ou fertirrigado, relação de formas ácidas para aldeídos nos derivados Vanilil-(Ac/Al) Vanilil $_{\text {e Siringil-(Ac/Al) }}$ Siringil $_{\text {, }}$ relação de hexoses (manose + galactose) para pentoses (glucose + xilose)Relação H/P e relação entre aminoaçúcares derivados da atividade fúngica (glucosamina) em relação à bacteriana (ácido murâmico)-Gluc/Ac. Mur. Médias seguidas da mesma letra minúscula para comparações entre resíduos (R. Grosso e Fino) para serapilheira e cultivos (EC e EF) para solo e mesma letra maiúscula para comparações entre cultivos (EC e EF) para serapilheira e local de coleta (L e EL) de solo não diferem entre si a 5\%, pelo teste LSD de Fisher protegido. $1 *$ e $2 *$ indicam diferença significativa entre resíduos de serapilheira para VSC e cultivos para aminoaçúcares no solo, respectivamente. Linha vertical indica erro-padrão da média $(\mathrm{n}=3)$.

Figure 1 - Content of lignin-derived phenols(VSC: Vanilil, Syringy land Cinnamyl) and carbohydrates in the coarse (R. Grosso) and fine ( $R$. Fine) residue in litter of conventional $(E C)$ and fertirrigated $(E F)$ eucalyptus and content of phenol derivatives lignin (VSC), carbohydrates and amino sugars in soil samples collected in the line $(L)$ and between-lines $(E L)$ of the conventional and fertirrigated eucalyptus, and relation of acid toaldehy desform

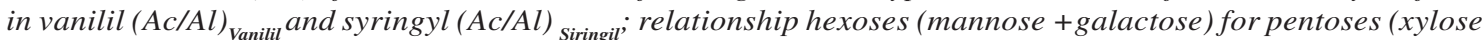
+ glucose)-ratio H/P, and relationship amino sugars derived of fungal (glucosamine) to bacteria lactivity (muramic acid)-Gluc/Ac. Mur. Means followed by same minuscule letter for comparisons between residue litter (R. Coarse and Fine) and cultivations (EC and EF) to soil and, same maiuscule letter for comparisons between cultivation (EC e EF) forresidue litter and collection site ( $L$ and EL) of soil did not differ at $5 \%$ by Fisher's protected LSD test. $1 *$ and $2 *$, indicate significant difference between litter residue to VSCand cultivations to amino sugars in soil, respectively. Vertical line indicates standard error of mean $(n=3)$.

Revista Árvore, Viçosa-MG, v.37, n.3, p.519-529, 2013 
provenientes da atividade microbiana. Também ocorreram diferenças significativas entre sistemas de cultivo para teor de aminoaçúcares, relações VSC/N e ácidos/aldeídos do grupamento vanilil da lignina (Ac/Al). Não foram observadas diferenças entre tratamentos nas relações $\mathrm{C} / \mathrm{N}$ e VSC/Carb.

A adoção da fertirrigação no solo cultivado com eucalipto propiciou aumento nos teores totais de lignina (VSC) e carboidratos, a qual incrementou os teores de COT e NT, principalmente nas amostras de solo coletadas nas entrelinhas (EL) de cultivo (Tabela 3), em que o aporte de resíduos do cultivo anterior foi maior.

Tabela 2 - Teores médios de C, N, fenóis derivados de lignina (VSC) e relação VSC/N nos resíduos grossos e finos da serapilheira de povoamentos de eucalipto nos sistemas convencional e fertirrigado, nos Tabuleiros Costeiros do Espírito Santo.

Table 2 -Average contents of $C, N$, lignin derived phenols (VSC) and relation VSC/N in the coarse and fine residue of litter of eucalypt plantation in conventional and fertirrigated systems in the Coastal Plains of Espírito Santo, ES, Brazil.

\begin{tabular}{lcccc}
\hline Serapilheira & COT & NT & VSC & VSC/N \\
\cline { 2 - 3 } & \multicolumn{2}{c}{ dag kg-1 $^{-1} \mathrm{~g} \mathrm{~kg}^{-1}$} \\
Resíduo grosso & 48,3B & $0,2 \mathrm{~B}$ & $89,2 \mathrm{~A}$ & $51,3 \mathrm{~A}$ \\
Resíduo fino & $52,1 \mathrm{~A}$ & $0,8 \mathrm{~A}$ & $29,6 \mathrm{~B}$ & $3,7 \mathrm{~B}$ \\
Média & 50,2 & 0,5 & 59,3 & 59,3 \\
Sig. p/ resíduo (\%) & 0,0 & 0,0 & 0,0 & 0,0 \\
C.V. $(\%)$ & 6,8 & 19,2 & 11,4 & 11,4 \\
\hline
\end{tabular}

Médias seguidas da mesma letra maiúscula na coluna não diferem entre si a 5\%, pelo teste LSD de Fisher protegido. Sig. p/ resíduo (\%): significância da análise de variância dos resíduos vegetais (resíduos grossos versus finos), em porcentagem. C. V. (\%): coeficiente de variação, em porcentagem.
Os grupamentos ácidos derivados da lignina foram ligeiramente superiores no solo coletado nas entrelinhas do cultivo fertirrigado (Figura 1), fazendo que a relação Ac/Al nos grupamentos vanilil e siringil também fosse maior. No solo da entrelinha do cultivo fertirrigado também se obtiveram maiores teores de manose e galactose, e, consequentemente, a relação H/P também foi maior nesse solo, em comparação com o solo da entrelinha do cultivo convencional (Figura 1).

Condizente com a relação H/P, também se obteve maior teor de aminoaçúcares totais no solo do sistema fertirrigado (Tabela 4), correspondente a $380,7 \mathrm{mg} \mathrm{kg}^{-1} \mathrm{e}$ $23 \%$ superior àquele obtido no sistema convencional (294,0 $\mathrm{mg} \mathrm{kg}^{-1}$ ). Entre os compostos microbianos, a glucosamina foi considerada o composto mais abundante nos solos, em comparação com a galactosamina e o ácido murâmico (Figura 1). Juntamente com o incremento dos carboidratos de origem microbiana das linhas e entrelinhas no solo do eucalipto fertirrigado, obteve-se aumento da relação glucosamina/ácido murâmico no solo fertirrigado a valores próximos a 48, bem superiores aos obtidos no solo da linha e entrelinha do eucalipto convencional, que foram iguais a 20 e 38 , respectivamente (Figura 1).

\section{DISCUSSÃO}

A redução no teor de carboidratos totais na serapilheira do eucalipto fertirrigado pode ser justificada pela maior intensidade de utilização dos carboidratos de origem vegetal (pentoses) por parte dos microrganismos do solo, que por sua vez aumentaram

Tabela 3 - Teores médios de carbono orgânico total (COT), nitrogênio total (NT), fenóis derivados de lignina (VSC) e carboidratos totais em amostras de solo coletadas na linha e entrelinha de povoamentos de eucalipto nos sistemas convencional e fertirrigado, nos Tabuleiros Costeiros do Espírito Santo.

Table 3 - Average contents of total organic carbon(TOC), total nitrogen (TN), lignin-derived phenols(VSC) and total carbohydrates in soil samples collected on line and between-line of eucalypt fertirrigated the conventional systems and in the Coastal Plains of Espírito Santo, ES, Brazil.

\begin{tabular}{|c|c|c|c|c|c|c|c|c|}
\hline \multirow{2}{*}{ Cultivo } & \multicolumn{2}{|c|}{ COT } & \multicolumn{2}{|c|}{ NT } & \multicolumn{2}{|c|}{ VSC } & \multicolumn{2}{|c|}{ Carboidratos } \\
\hline & Linha & Entrelinha & Linha & Entrelinha & Linha & Entrelinha & Linha & Entrelinha \\
\hline \multirow[b]{2}{*}{ Convencional } & & $\mathrm{g} \mathrm{k}$ & & - & 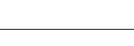 & $\mathrm{mg}$ & -1 & \\
\hline & $9,6 \mathrm{aB}$ & $6,2 \mathrm{bB}$ & $0,7 \mathrm{aB}$ & $0,5 \mathrm{aB}$ & $124,1 \mathrm{aA}$ & $100,8 \mathrm{bB}$ & $3120,2 \mathrm{aB}$ & $2063,0 \mathrm{bB}$ \\
\hline Fertirrigado & $11,2 \mathrm{bA}$ & $12,8 \mathrm{aA}$ & $1,0 \mathrm{bA}$ & $1,3 \mathrm{aA}$ & $78,4 \mathrm{bB}$ & $116,0 \mathrm{aA}$ & $3847,5 \mathrm{bA}$ & $4292,5 \mathrm{aA}$ \\
\hline Média & \multicolumn{2}{|r|}{9,9} & \multicolumn{2}{|c|}{0,9} & \multicolumn{2}{|c|}{104,8} & \multicolumn{2}{|c|}{3330,8} \\
\hline Sig. Inter. $(\%)$ & \multicolumn{2}{|r|}{0,4} & \multicolumn{2}{|c|}{3,8} & \multicolumn{2}{|c|}{0,1} & \multicolumn{2}{|c|}{0,3} \\
\hline C. V. $(\%)$ & \multicolumn{2}{|r|}{9,7} & \multicolumn{2}{|c|}{18,2} & \multicolumn{2}{|c|}{8,1} & \multicolumn{2}{|c|}{8,4} \\
\hline
\end{tabular}

Médias seguidas da mesma letra minúscula na linha e maiúscula na coluna não diferem entre si a 5\%, pelo teste LSD de Fisher protegido. Sig. Int. (\%): significância da interação entre sistemas de cultivo (convencional e fertirrigado) versus locais de coleta (linha e entrelinha), em porcentagem. C. V. $(\%)$ : coeficiente de variação, em porcentagem. 
Tabela 4 - Teor médio de aminoaçúcares e relação C/N, VSC/ $\mathrm{N} \mathrm{e} \mathrm{VSC/Carb} \mathrm{nos} \mathrm{solos} \mathrm{de} \mathrm{povoamentos} \mathrm{de} \mathrm{eucalipto}$ nos sistemas convencional e fertirrigado, nos Tabuleiros Costeiros do Espírito Santo.

Table 4-Average content of amino sugar sand C/N, VSC/ VSCandN/Carbratio in soils of eucalypt plantation in the conventional and fertirrigated systems in the Coastal Plains of Espírito Santo, ES, Brazil.

\begin{tabular}{lcccc}
\hline Cultivo & Aminoaçúcares & C/N & VSC/N & VSC/Carb \\
\cline { 2 - 4 } Convencional & $294,0 \mathrm{~B}$ & 12,9 & $0,16 \mathrm{~A}$ & 0,4 \\
Fertirrigado & $380,7 \mathrm{~A}$ & 10,2 & $0,10 \mathrm{~B}$ & 0,3 \\
Média & 337,3 & 11,6 & 0,13 & 0,3 \\
Sig. p/cultivo(\%) & 5,0 & $\mathrm{~ns}$ & 0,8 & $\mathrm{~ns}$ \\
C. V. $(\%)$ & 19,1 & 25,5 & 24,9 & 26,1 \\
\hline
\end{tabular}

Médias seguidas da mesma letra maiúscula na coluna não diferem entre si a 5\%, pelo teste LSD de Fisher protegido. Sig. p/cultivo (\%): significância da análise de variância dos sistemas de cultivo (convencional versus fertirrigado), em porcentagem. C. V. (\%): coeficiente de variação, em porcentagem.

aqueles de origem microbiana (hexoses) na serapilheira, em comparação com o do cultivo convencional. E isso pode ser comprovado pelo aumento da relação hexoses/ pentoses $(\mathrm{H} / \mathrm{P})$ na serapilheira do sistema fertirrigado $(\mathrm{EF}=0,28$ e $\mathrm{EC}=0,22$ ) (Figura 1). A maior disponibilidade de água e nutrientes, especialmente o NT, no solo e, ou, no do sistema fertirrigado pode ter estimulado a produção de enzimas responsáveis pela degradação da celulose (celulase) e o aumento da relação hexoxes/ pentoses no solo (CARREIRO et al., 2000).

$\mathrm{O}$ teor de carboidratos e as relações $\mathrm{C} / \mathrm{N}$ e VSC/ Carb foram maiores nos resíduos grossos nos dois sistemas de cultivo, em comparação com os resíduos finos da serapilheira (Tabela 1). Por sua vez, os resíduos finos tiveram maior teor de COT e NT e menor teor de VSC e relação VSC/N, em comparação com os resíduos grossos (Tabela 2). Tais resultados indicam que os resíduos finos da serapilheira de eucalipto convencional e fertirrigado apresentam-se mais decomponíveis aos microrganismos do solo. Segundo Pegoraro et al. (2011b), a redução da relação VSC/N e C/N da serapilheira pode aumentar a atividade microbiana no solo e favorecer a estocagem de COT e NT na MOS.

Os compostos fenólicos que mais contribuíram para a lignina (VSC) da serapilheira foram, em média, o siringaldeído (59\%), a acetossiringona (12\%) e o ácido siríngico (11\%). Esses compostos foram encontrados, principalmente, nos resíduos grossos (RG), cujos teores foram superiores aos obtidos no compartimento mais fino (RF), levando à maior contribuição do grupamento siringil para a VSC da serapilheira (Figura 1). Tais resultados foram concordantes com os obtidos por Pegoraro et al. (2011a), que obtiveram elevados teores de siringaldeído $\left(50,6 \mathrm{~g} \mathrm{~kg}^{-1}\right)$ e ácido siríngico $\left(9,1 \mathrm{~g} \mathrm{~kg}^{-1}\right)$ nos resíduos de galhos grossos da serapilheira de eucalipto, indicando maior estabilidade dos resíduos grossos da serapilheira à ação decompositora da comunidade microbiana. Segundo Costa et al. (2005), há alta correlação positiva entre o teor de lignina e a massa remanescente de serapilheira foliar (folhedo recém-caído) em plantios de E. grandis incubados durante um período de 382 dias, devido à maior recalcitrância de fenóis constituintes da lignina.

A maior participação de tecidos de sustentação nos resíduos grossos pode ter favorecido a alocação de lignina nesse compartimento. A lignina é importante componente das células da parede celular de plantas vasculares e, junto com a hemicelulose, constitui as paredes primária e secundária e a lamela média dos espaços entre microfibrilas de celulose, atuando como conexão entre células, além de servir como reforço da parede celular do tecido xilemático (KÖGEL-KNABNER, 2002).

O teor médio de lignina (VSC) no solo de eucalipto foi de $105 \mathrm{mg} \mathrm{kg}^{-1}$ (11 $\mathrm{g} \mathrm{kg}^{-1}$ de COT). Esse resultado foi similar ao obtido por Lobe et al. (2002), que encontraram teores médios de $132 \mathrm{mg} \mathrm{kg}^{-1}$ em solos arenosos de pastagem nativa na África e inferiores aos obtidos por Spielvogel et al. (2007), que obtiveram teores médios de lignina de aproximadamente $30 \mathrm{~g} \mathrm{~kg}^{-1}$ de COT em horizonte superficial (Ah) de solos com 25 anos de floresta de Picea abies L. [Karst.].

No solo do sistema fertirrigado, a adição de água e nutrientes parece ter induzido ao maior teor de lignina e carboidratos, principalmente nas entrelinhas de cultivo, quando comparado com aqueles do solo do cultivo convencional (Tabela 3 ). Três fatores principais podem ter contribuído para a ocorrência de tais resultados: o primeiro seria o maior aporte de serapilheira pelo cultivo do eucalipto fertirrigado; o segundo seria a predominância de resíduos finos na serapilheira ( $\mathrm{EF}=60 \%$ e $\mathrm{EC}=40 \%$, em relação ao total) (Tabela 1), que, juntamente com a maior disponibilidade de água e nutrientes no solo, parece ter favorecido o aumento da atividade decompositora de resíduos mais lábeis e a preservação dos mais lignificados. Um terceiro fator 
estaria relacionado à proliferação de raízes finas nas entrelinhas devido à maior disponibilidade de nutrientes reciclados. Combinados, esses três fatores podem ter favorecido também o incremento de COT e NT na MOS.

Os grupamentos ácidos derivados da lignina foram ligeiramente superiores no solo coletado nas entrelinhas do cultivo fertirrigado (Figura 1), fazendo que a relação Ac/Al nos grupamentos vanilil e siringil também fosse maior e indicando estádio mais avançado de oxidação da lignina no sistema fertirrigado, principalmente na entrelinha de cultivo, em decorrência, possivelmente, da maior atividade microbiana nesse sistema e local. Outros estudos também têm mostrado efeito substancial da irrigação e, ou, da fertilização nos compostos fenólicos do solo, com reflexo no teor de MOS. O acúmulo de $\mathrm{C}$ de grupamentos carbonil e alquil e a perda de grupamentos metoxil e O-alquil no solo, três anos após a incubação de serapilheira de Pinus, identificados por meio de CPMAS 13C-NMR, foram maiores no sistema fertilizado e, ou, irrigado, evidenciando o incremento de $100 \%$ na decomposição do serapilheira no tratamento fertilizado e $62 \%$ no irrigado, em comparação com o tratamento-testemunha (sem irrigação e fertilização) (SANCHEZ, 2004). Em cultivos anuais manejados em rotação (soja-trigo), a adição de fertilizantes contribuiu substancialmente para o aumento da atividade microbiana do solo, refletindo em incremento no teor de $\mathrm{C}$ e de $\mathrm{N}$ da biomassa microbiana e carboidratos hidrolisáveis em $\mathrm{H}_{2} \mathrm{SO}_{4}$ 1,5 $\mathrm{mol} \mathrm{L}^{-1}$ (MANNA et al., 2007).

Um forte indicativo do aumento da atividade microbiana na entrelinha do solo do eucalipto fertirrigado foi o incremento dos carboidratos de origem microbianahexoses (manose e galactose) em relação àqueles de origem vegetal-pentoses (arabinose e xilose, entre outros), ou seja, maior relação H/P(Figura 1). O diferencial dessa condição parece ter sido a maior oferta de substrato nas entrelinhas, aliada à adição de água e fertilizantes, incrementando, ao longo do tempo, a atividade microbiana e a presença de carboidratos dela derivados. Tais resultados também foram corroborados pela maior presença de compostos derivados da atividade microbiana no solo de eucalipto fertirrigado.

Entre os compostos de origem microbiana, a maior presença de glucosamina no solo fertirrigado implicou incremento da relação glucosamina/ácido murâmico (Figura 1), indicando a maior contribuição da comunidade fúngica na produção de aminoaçúcares, em comparação com aquela do eucalipto convencional. Esses resultados corroboram aqueles obtidos por Solomon et al. (2001), que verificaram maior teor de glucosamina nos solos e relação glucosamina/ácido murâmico aumentada de 14 no solo de floresta nativa para 26 no solo cultivado, indicando aumento da atividade fúngica em comparação com a bacteriana. O incremento de glucosamina na entrelinha do solo do eucalipto fertirrigado também pode ser vinculado à maior deposição de serapilheira (tanto de resíduos grossos quanto finos), uma vez que tais resíduos são decompostos preferencialmente pela comunidade fúngica, por serem resíduos considerados recalcitrantes quando comparados a resíduos de outras espécies vegetais, como pastagens com gramíneas (PEGORARO et al., 2011b) e leguminosas arbóreas.

Cabe salientar, no entanto, que a presença de actinomicetos e bactérias podem ter auxiliado, em menor proporção, para tal resultado, já que estudo realizado por Glaser et al. (2004) também indicou a presença de glucosamina em isolados de origem bacteriana e de actinomicetos no solo, diferentemente do ácido murâmico, que foi encontrado somente em isolados de bactérias. Como o teor de glucosamina foi similar entre os cultivos, a relação glucosamina/ácido murâmico mais estreita no solo do sistema convencional (20) indica a maior contribuição bacteriana no processo de decomposição e formação da MOS do que no solo do sistema fertirrigado.

Essas alterações na comunidade microbiana do solo têm implicações diretas no processo de humificação da MOS e na agregação do solo. Acredita-se que a maior atividade fúngica, por meio de extensa rede de hifas, possa favorecer a agregação de partículas de solo com compostos orgânicos, além de apresentarem biomassa com parede celular rica em melanina e quitina, polímeros muito mais resistentes à degradação do que fosfolipídeos (ricos em energia), principais constituintes da biomassa bacteriana (BAILEY et al., 2002). Essa estocagem resulta em compostos mais resistentes à decomposição realizada por fungos e mais lábeis quando realizada em maior proporção por bactérias (HE et al., 2011).

\section{CONCLUSÕES}

O cultivo de eucalipto fertirrigado promove maior produção de matéria seca na serapilheira, especialmente de resíduos finos e mantém o teor de lignina, carbono orgânico total, nitrogênio total, relação entre o teor de compostos derivados de lignina/teor de nitrogênio total e reduz o teor total de carboidratos na serapilheira, em comparação com aquela de eucalipto sob sistema

Revista Árvore, Viçosa-MG, v.37, n.3, p.519-529, 2013 
convencional. Mas no solo, com eucalipto sob sistema fertirrigado, o teor de carboidratos totais, lignina, aminoaçúcares, carbono orgânico total e nitrogênio total são maiores, principalmente nas entrelinhas de cultivo, em comparação com o sistema convencional.

A lignina presente no solo fertirrigado tem estádio mais avançado de oxidação e aumento da presença de compostos originários da atividade microbiana no solo, que por sua vez se caracteriza pela maior relação glucosamina/ácido murâmico, o que indica maior contribuição de aminoaçúcares originados da atividade fúngica em relação à bacteriana.

\section{REFERÊNCIAS}

BAILEY, V. L. et al. Fungal-to-bacterial ratios in soils investigated for enhanced $\mathrm{C}$ sequestration. Soil Biology \& Biochemistry, v.34, n.7, p.997-1007, 2002.

BAtaglia, O. C. et al. Métodos de análises químicas de plantas. Campinas: Instituto Agronômico de Campinas, 1983. 48p. (Boletim, 78).

BAUMANN, K. et al. Residue chemistry and microbial community structure during decomposition of eucalypt, wheat and vetch residues. Soil Biology \& Biochemistry, v.41, n.9, p.1966-1975, 2009.

CARREIRO, M. M. et al.Microbial enzyme shifts explain litter decay responses to simulated nitrogen deposition. Ecology, v.81, n.9, p.23592365, 2000.

COSTA, G. S.; GAMA-RODRIGUES, A. C.; CUNHA, C. M. Decomposição e liberação denutrientes da serapilheira foliar em povoamentosde Eucalyptus grandis no Norte Fluminense. Revista Árvore, v.29, n.4, p.563-570, 2005.

FORRESTER, D. I. et al. Carbon allocation in a mixed-species plantation of Eucalyptus globulus and Acacia mearnsii. Forest Ecology and Management, v.233, n.2/3, p.275-284, 2006.

GLASER, B. et al. Amino sugars and muramic acid-biomarkers for soil microbial community structure analysis. Soil Biology \&

Biochemistry, v.36, n.3, p.399-407, 2004.
GOÑI, M. A.; MONTGOMERY, S. AlcalineCuO oxidation with a microwave digestion system: lignin analyses of geochemical samples. Analytical Chemistry, v.72, n.14, p.31163121, 2000.

HE, H. et al. Temporal responses of soil microorganisms to substrate addition as indicatedby amino sugar differentiation. Soil Biology \& Biochemistry, v.43, n.6, p.1155-1161, 2011.

HEIM, A.; SCHMIDT, M. W. I. Lignin turnover in arable soil and grassland analysed with two different labelling approaches. European Journal of Soil Science, v.58, n.3, p.599608, 2007.

KÖGEL-KNABNER, I. The macromolecular organic composition of plant and microbial residues as inputs to soil organic matter. Soil Biology \& Biochemistry, v.34, n.2, p.139-162, 2002.

LEGGET, Z. H.; KELTING, D.L. Fertilization effects on carbon pools in loblolly pine plantations on two upland sites. Soil Science Society of America Journal, v.70, n.1, p.279-286, 2006.

LEITE, L. F. C. et al. Estoques totais de carbono orgânico e seus compartimentos em Argissolo sob floresta e sob milho cultivado com adubação mineral e orgânica. Revista Brasileira de Ciência do Solo, v.27, n.5, p.821-832, 2003.

LI, Y. et al. Effects of nutrient additions on ecosystem carbon cycle in a Puerto Rican tropical wet forest. Global Change Biology, v.12, n.2, p.284-293, 2006.

LIANG, C. et al. Effect of plant materials on microbial transformation of amino sugars in three soil microcosms. Biology and Fertility of Soils, v.43, n.6, p.631-639, 2007.

LOBE, I. et al. Influence of prolonged arable cropping on lignin compounds in sandy soils of the South African Highveld. European Journal of Soil Science, v.53, n.4, p.553-562, 2002. 
MADEIRA, M. V. et al. Changes in carbon stocks in Eucalyptus globulusLabill. plantations induced by different water and nutrient availability. Forest Ecology and Management, v.171, n.1/2, p.75-85, 2002.

MANNA, M. C. et al. Long-term fertilization, manure and liming effects on soil organic matter and crop yields. Soil and Tillage

Research, v.94, n.2, p.397-409, 2007.

MARTENS, D. A.; LOEFFELMANN, K.L.

Improved accounting of carbohydrate carbon from plants and soils. Soil Biology \&

Biochemistry,v.34, n.10, p.1393-1399, 2002.

MÖLLER, A. et al. Lignin, carbohydrate, and amino sugar distribution and transformation in the tropical highland soils of northern Thailand under cabbage cultivation, pinus reforestation, secondary forest, and primary forest. Australian Journal Soil Research, v.40, n.6, p.977-998, 2002.

OMETTO, J. C. Bioclimatologia vegetal. São Paulo: Ceres, 1981. 425p.

OTTO, A.; SIMPSON, M.J. Evaluation of CuO oxidation parameters for determining the source and stage of lignin degradation in soil.

Biogeochemistry, v.80, n.2, p.121-142, 2006.

PEGORARO, R. F. et al. Biomarcadores derivados de planta e de microrganismos em solos de tabuleiros costeiros cultivados com eucalipto e acácia. Ciência Florestal, v.22, n.4, p.733-746, 2012.

PEGORARO, R. F. et al. Fenóis derivados da lignina, carboidratos e aminoaçúcares em serapilheira e solos cultivados com eucalipto e pastagem. Revista Árvore, v.35, n.2, p.359-370, 2011a.

PEGORARO, R. F. et al. Estoques de carbono e nitrogênio nas frações da matéria orgânica emArgissolosob eucalipto e pastagem. Ciência Florestal, v.21, n.2, p.341-354, 2011b.

SANCHEZ, F. G. Irrigation, fertilization and initial substrate quality effects on decomposing Loblolly pine litter chemistry. Plant Soil, v.270, n.1, p.113-122, 2004
SJÖBERG, G. et al. Degradation of hemicellulose, cellulose and lignin in decomposing spruce needle litter in relation to N. Soil Biology \& Biochemistry,v.36, n.11, p.1761-1768, 2004.

SOLOMON, D. et al. Land use effects on amino sugar signature of chromic Luvisol in the semi-arid part of northern Tanzania.

Biology and Fertility of Soils, v.33, n.1, p.33-40, 2001.

SPIELVOGEL, S. et al. Changes of lignin phenols and neutral sugars in different soil types of a high-elevation forest ecosystem 25 years after forest dieback. Soil Biology \&

Biochemistry, v.39, n.2, p.655-668, 2007.

STAPE, J. L. et al. Estimativa da produtividade de povoamentos monoclonais de

Eucalyptusgrandis x E. urophylla no Nordeste do Estado da Bahia-Brasil em função das variabilidades pluviométrica e edáfica. In: IUFRO CONFERENCE ON SILVICULTURE AND IMPROVEMENT OF EUCALYPTS, 1997, Salvador. Proceedings...Salvador:EMBRAPA/ CNPF, 1997. p.192-198.

STAPE, J. L.; RYAN, G.M.; BINKLEY, D. Testing the utility of the 3-PG model for growth of Eucalyptus grandis $\mathrm{x}$ urophylla with natural and manipulated supplies of water and nutrients.

Forest Ecology and Management, v.193, n.1/2, p.219-234, 2004.

STEEL, R. G. D. et al. Principles and procedures of statistics: a biometrical approach. New York: McGraw-Hill, 1997. 666p.

YEOMANS, J. C.; BREMNER, J.M. A rapid and precise method for routine determination of organic carbon in soil.Communications in Soil Science and Plant Analysis, v.13, n.13, p.1467-1476, 1988.

ZHANG, X.; AMELUNG, W. Gas chromatographic determination of muramic acid, glucosamine, mannosamine, and galactosamine in soils. Soil Biology \& Biochemistry, v.28, n.9, p.1201-1206, 1996. 
